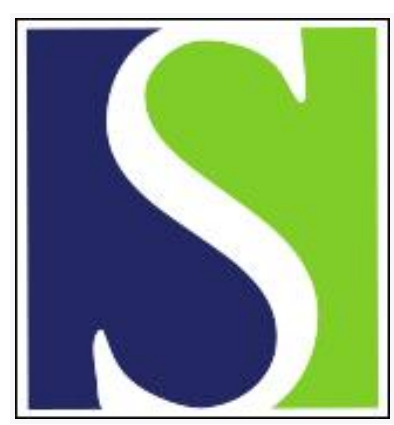

Scand J Work Environ Health 1992;18(2):133-141

https://doi.org/10.5271/sjweh.1599

Issue date: 01 Apr 1992

Cancer mortality and incidence in mastic asphalt workers. by Wong $\mathrm{O}$, Bailey WJ, Amsel J

This article in PubMed: www.ncbi.nlm.nih.gov/pubmed/1604275




Scand J Work Environ Health 1992;18:133-41

\section{Cancer mortality and incidence in mastic asphalt workers}

In a recent publication, Hansen (1) described the mortality of a cohort of 679 male mastic asphalt workers in Denmark. The cohort in this report was the same as the one in a previous report which described cancer incidence (2). We would like to offer some comments on these two papers.

The cohort of mastic asphalt workers was assembled apparently through a variety of data sources, including employment lists, union records, and benefit society files covering the period 1959-1980. There was very little discussion on the method of constructing the cohort. The completeness, representativeness, or quality of the source documents was not discussed in either publication. Depending on the original purposes in creating these particular lists of employees, potential selection biases might be associated with these lists.

One striking observation of this study was the high overall mortality for the cohort [standardized mortality ratio (SMR) 163]. This finding was unusual because the overall mortality of an occupational group is usually slightly lower than that of the general population (the "healthy worker effect"), the major mortality deficit coming from circulatory diseases. The healthy worker effect is the most prominent during the period following hire.

A closer examination of the 1991 Hansen data indicated that the overall mortality excess came primarily from the younger age groups. In fact, there was a negative trend of overall mortality by age (dropping from an SMR of 345 in the 15- to 39-year age group to 119 for the 65- to 89-year age group). Furthermore, among those aged 15-39 years, the SMR for circulatory diseases was $882(\mathrm{P}<0.05)$. The author indicated that most mastic asphalt workers were hired in their twenties. Therefore, the 15- to 39-year age group would represent the experience for the period following hire and should show the healthy worker effect, if any, the most prominently.

Contrary to the author's claim, the negative trend indicates that there was no healthy worker effect and that selection bias was likely operating in the opposite direction. That is, a higher proportion of individuals with health problems, for reasons not identified in the reports, were hired into that particular industry in Denmark. This observation of potential selection bias reinforced the need for examining closely how the cohort was assembled.

Another striking feature of this cohort was the significant increase in mortality due to cirrhosis of the liver (SMR 467, P<0.05). The most likely explanation for this increase was excess alcohol consumption. Further evidence of excess alcohol consumption came from the elevated incidence ratios for cancers of the mouth, esophagus, liver, and larynx (2). These findings again suggested that some of the workers had a life-style that might adversely affect their health. No adjustment was made to account for the apparent excess alcohol consumption.

Hansen (1), however, did make an attempt to adjust for the confounding effects due to smoking and urbanization. There were some problems or limitations in her adjustment however. To estimate the effect of cigarette smoking, she relied on the risk estimates provided in the "British Doctor Study" (3). For "medium" smokers, the relative risk used by Hansen was 7.8, and for "heavy" smokers it was 18.9. It appeared that Hansen might have used incorrect (lower) risk estimates. Doll \& Peto (3) reported the following lung cancer relative risks for four categories of smokers by daily cigarette consumption: nonsmokers 1.0, light smokers (1-14 cigarettes/day) 7.8, medium smokers (15-24 cigarettes/day) 12.7, and heavy smokers ( $\geq 25$ cigarettes/day) 25.1 . The risk estimates reported by Doll \& Peto for medium and heavy smokers were higher than those used by Hansen. Hansen appeared to have combined the medium and heavy smokers into a single "heavy" category. Other studies have reported even higher relative risks for medium or heavy smokers, especially if the histological types are considered. The 1989 Hansen report listed information on the cell type for all of the lung cancer cases, and most belonged to Kreyberg's group I, which is tobacco-related. The relative risks for Kreyberg's group I lung cancer due to smoking are much higher than those for lung cancer in general. For United States veterans who smoked more than two packs of cigarettes a day, the relative risk for lung cancer was 31-fold (4). Wynder \& Stellman (5) reported a relative risk of more than 60 -fold for United States males who smoked two packs of cigarettes a day for more than 10 years. Thus Hansen might have underestimated the effect of smoking in her adjustment.

Furthermore, Hansen relied on an "inquiry" for the prevalence of smoking in the cohort. It was not clear whether the sample included in the inquiry was representative of the actual cohort. In addition, duration of smoking was not considered in her adjustment. Thus her adjustment for smoking was inadequate and probably represented an underadjustment at best.

With respect to the adjustment for urbanization, there was a considerable discrepancy between the adjustment factor for lung cancer used in the 1989 cancer incidence paper $(35 \%)$ and the one used in the 1991 mortality paper (10\%). The 1991 mortality paper sub- 
stantially underestimated the effect of urbanization on lung cancer.

There were problems in the statistical analyses as well. First, only lung cancer was given a separate sitespecific analysis. All other sites were lumped together into the category "nonpulmonary cancer." The latter category was meaningless. The reason for not analyzing these cancer sites separately was that, according to the author, no Danish rates for cancer sites other than the lung were available. It is difficult to believe that a developed country such as Denmark does not have basic cancer death rates.

Another problem associated with the statistical analysis was the crude age adjustment. The age groups used were very wide. For example, Hansen lumped those between ages 40 to 54 years into one single age group. Within this 15-year span, the rate of lung cancer varies widely. For white males aged $40-54$ years in the United States in the 1970s, the age-specific mortality rates for respiratory cancer were as follows: $40-44$ years: 19.14 per $100000,45-49$ years: 46.77 per $100000,50-54$ years: 90.53 per 100000 . Thus, within this 15-year age group, there was an almost fivefold difference. Using such wide age groups for adjustment could easily lead to either an under- or overestimation of the SMR values, depending on the age make-up of the cohort.

The author also analyzed the data by birth cohort. This analysis was interesting for the following reason. Since most mastic asphalt workers were hired in their twenties, the birth cohort could be regarded as an approximation for latency. The results of the birth cohort analysis was not piesented, but the author stated that the analysis "revealed no consistent trend." This statement is important in the interpretation of the results. In the 1989 paper, the author used age group as a proxy for latency and length of employment, on the assumption that most mastic asphalt workers were hired in their early twenties. In table 3 of the paper (2), the lung cancer SMR for those aged 40-89 years was 344 ( 27 observed versus 7.85 ). This group would represent latency and length of employment of more than 20 years. On the basis of the numbers reported, the lung cancer SMR for those aged less than 40 years (with a latency and length of employment shorter than 20 years) was calculated to be 370 (4 observed versus 1.08 expected). Thus there was no upward trend associated with either latency or length of employment.

In the 1989 paper, using birth-year subcohorts, the author concluded that those not exposed to coal tar but to asphalt (subcohort III consisting of those born in 1930-1960, table 5 of the paper) were also at an increased risk of lung cancer (SMR 857, P<0.05). However, this finding was based on only three deaths. A misclassification of even one case would have changed the result.

In addition, the birth dates of the three cases were 1930, 1931, and 1934; two of the three were actually very close to the division between subcohorts II and
III, and exposure to coal tar could have been possible. Furthermore, all three cases were smokers. Thus the conclusion that exposure to asphalt only could also increase lung cancer risk was based on extremely inadequate data.

Finally, the issue of exposures received by these mastic asphalt workers must be examined carefully. According to Hansen, coal tar was not used in the production of mastic asphalt in Denmark except during World War II. As such, coal tar certainly was a confounding exposure for those who worked during World War II. In fact, the use of coal tar in the asphalt industry might have been severely underestimated by Hansen. According to sources in the Danish asphalt industry, both tar oil and tar pitch were used in the asphalt industry in Denmark up to as recently as 1975 (6). Furthermore, coal tar was used in leveling the "base" asphalt layer (so-called "pulver" asphalt) until the earlier 1970s. Thus the Danish mastic asphalt workers in the Hansen cohort were exposed to both bitumen asphalt fumes and coal tar, the latter being a known human carcinogen.

To summarize, there were several serious limitations associated with the Hansen papers $(1,2)$. First, there was concern regarding the source data for constructing the cohort. The completeness, representativeness, or quality of the cohort could not be assessed on the basis of the information presented in the report. Some findings in the study suggested that selection bias was likely and life-style risk factors should be examined carefully for these mastic asphalt workers.

Second, the causes of death with significant excesses were related to either smoking or alcohol consumption. Urbanization was also a confounding factor. The post hoc adjustment made by the author was inadequate and tended to underestimate the effects of these confounding factors.

Third, basic employment histories were not available, and therefore standard analyses by duration or latency were infeasible. In the presence of strong confounders such as smoking, alcohol consumption, and coal tar, little could be said about asphalt fumes without detailed exposure-response analyses.

Finally, the author appeared to down play the significance of coal-tar exposure in the cohort. Although the author admitted that coal tar was used during World War II, her conclusion attributed the cancer excess mainly to bitumen fumes. Other knowledgeable sources reported that coal tar was a much more serious confounder than Hansen led to suggest.

In conclusion, these two papers do not offer any firm data to support the author's conclusion that bitumen fumes were responsible for the observed elevated mortality from lung cancer among mastic asphalt workers.

\section{References}

1. Hansen ES. Mortality of mastic asphalt workers. Scand J Work Environ Health 1991;17:20-4. 
2. Hansen ES. Cancer incidence in an occupational cohort exposed to bitumen fumes. Scand J Work Environ Health 1989;15:101-5.

3. Doll R, Peto R. Mortality in relation to smoking: 20 years' observations on male British doctors. Br Med J 1976; 2:1525-36.

4. Public Health Service. Smoking and health, report of the Advisory Committee to the Surgeon General of the Public Health Service. Washington, DC: Public Health Service, 1964. (Public Health Service publication; no 1103).

5. Wynder EL, Stellman SD. Impact of long-term filter cigarette usage on lung and larynx cancer risk: a case-control study. J Natl Cancer Inst 1979;62:471-7.

6. Eriksen PB. Mastic asphalt industry in Denmark 19391976. Presented at the Symposium on Health Aspects of Asphalt Production and Paving, Stockholm, 7-8 June 1990.

Otto Wong, $\mathrm{ScD},{ }^{1}$ William J Bailey, MPH, ${ }^{2}$ Jon Amsel, $\mathrm{ScD}^{3}$

${ }^{1}$ Applied Health Sciences 181 Second Avenue, Suite 628, PO Box 2078, San Mateo, CA 94401, USA.

2 Chevron Corporation, Medical Staff, 225 Bush Street, San Francisco, CA 94104, USA.

${ }^{3}$ Owens-Corning Fiberglas, Fiberglas Tower, Toledo, OH 43659, USA.

\section{Author's reply}

First, the reader should know that the United States (US) Occupational Safety and Health Administration (OSHA) has started negotiations with the US asphalt industry about lowering the threshold limit value for bitumen fumes. The follow-up study on Danish mastic asphalt workers $(1-2)$, to which the preceding letter refers, constitutes one part of the documentation presented by OSHA on this issue.

In short, the follow-up study on Danish mastic asphalt workers showed a twofold increased cancer incidence, mainly due to a 3.5 -fold increase for respiratory cancer and a 2.3-fold increase for digestive cancer (1). The overall mortality was increased 1.6 times, mainly because of a 2.3 -fold increase in cancer mortality. The mortality from circulatory diseases equaled that expected, whereas the increase was 2.1 times for chronic bronchitis, emphysema, and asthma, 4.7 for liver cirrhosis, and 1.7 for other diseases. In addition, the mortality from external causes was increased 2.2 times (2).

On 13 March 1991, representatives of the American and European asphalt industry paid a visit to the University of Copenhagen to discuss my study on mastic asphalt workers. The industry representatives included three persons from the US Asphalt Institute, namely Mr AJ Kriech, Mr WJ Bailey, and Mr J Amsel, and two representatives of Concawe, which is an organization of European oil companies.
Apparently, the representatives of the US Asphalt Institute find that some aspects of my study need to be elucidated further. What follows is a detailed answer to the criticism raised by Wong, Bailey, \& Amsel in their letter to the editor.

\section{Identification of the cohort members}

The study in question was performed as a follow-up of a historical cohort. In Denmark, mastic asphalt workers constitute a very small occupational group which has been split up in several companies. The nonexistence of a single file containing historical identification data for all mastic asphalt workers led to the enrollment of study subjects from the following data sources (see the appendix for details):

Sources 1-3: cumulative employment lists (or extracts of such lists) compiled by plant managements. The lists were handed over to Dr O Horwitz and Dr F Behrendt prior to 1 January 1978. Dr Horwitz and Dr Behrendt planned to perform a study on the mortality of mastic asphalt workers, but their plans were crossed by the sudden death of Dr Horwitz in 1980. Thereafter Dr Behrendt simply filed the data.

Sources 4-6: cross-sectional employment lists compiled in 1960 by plant managements on request of the head of the Copenhagen union of mastic asphalt workers, who needed a mailing list for the celebration of the union's 50-year anniversary on 28 February 1961.

Sources 7-8: cross-sectional employment lists compiled on particular occasions in 1972 and 1980.

Sources 9-10: membership files (from the 1970s) of the Copenhagen union of mastic asphalt workers. In this context it should be noted that nearly $100 \%$ of Danish workers are members of a trade union and that in Denmark we have not had competing unions.

Sources 11-12: membership files (from 1959 through January 1979) of a benefit society organized by the workers at one of the mastic asphalt plants. Membership of the benefit society was voluntary and could be obtained and retained by active workers only. In the case of short-term sick leave, the society paid the members partial compensation for lost wages.

\section{Possible outcome-dependent selection for entry?}

To ensure the correspondence between the cases recorded and the counts for person-years at risk, no person should be entered into a cohort study prior to the date on which the source from which he or she has 
been identified can be considered "closed." This has particular relevance for historical cohort studies in which employment or membership lists are compiled a posteriori. As an example, it is usually less easy for a management person to remember a prior worker who died several years ago than it is to remember his work mate who is still on the company's payroll. Similarly, membership cards for deceased persons are likely to be routinely discarded from a union or society membership file.

For these reasons, the persons identified from sources $1-3$ inclusive were not entered into the study prior to the time that the files in question had been handed over to Dr O Horwitz and Dr F Behrendt. As a result of this restrictive practice 40 deaths among mastic asphalt workers have not been included because they occurred prior to the stipulated date of entry.

However, as regards source 11 (the card-based membership file of a benefit society), it is likely that the subjects were entered too early (ie, by their individual date of entry into the benefit society). This possibility is indicated by the fact that the list of persons obtaining compensation from the same benefit society 19601966 (source 12) includes at least 55 persons not found in source 11 (the society's membership file covering the period 1959-1979). Furthermore, none of the six deaths among persons identified from source 11 occurred before 1 February 1979. These observations render credibility to the suspicion that membership cards of persons who died have been currently removed from the card file (source 11) until the closing down of the benefit society on 1 February 1979. Consequently, the date of entry into the study from source 11 should have been 1 February 1979. The inclusion of too many (maximum 763) person-years at risk for the 38 persons enrolled from source 11 has biased the study results slightly in a negative direction.

\section{Removal of duplicate records}

The raw data contained a number of "duplicate records" reflecting multiple recording of some of the subjects. In such cases the subject in question was entered into the study from the "oldest" valid source (ie, the source which, first, gave sufficient and valid identification data and, second, gave as long a period of follow-up as possible). This practice yielded a maximum number of person-years at risk without affecting the number of cases. As a result, the study rather underestimates than overestimates the effect.

\section{Regarding completeness and representativeness}

For some unknown reason, Wong, Bailey, \& Amsel raise the question of completeness and representativeness in their letter. Whereas completeness and representativeness are important in descriptive epidemiologic studies, it is generally a nonissue in analytical epidemiologic studies.

\section{Possible outcome-dependent selection for} censuring?

All of the 679 mastic asphalt workers included in the study were followed until the date of death, the date of emigration, or the overall closing date, whichever occurred earliest. Except for the six emigrants, the vital status of every study person was known by the closing date. The application of the standard procedure for unbiased censuring and the $100 \%$ follow-up of the cohort ensures that outcome-dependent selection for censuring did not take place.

\section{The so-called "healthy worker effect"}

Wong, Bailey, \& Amsel claim that the observation of an increased overall mortality among mastic asphalt workers should indicate an opposite "healthy worker effect" and suggest that the job as mastic asphalt worker has in particular attracted individuals with health problems.

For the evaluation of the mortality pattern it may be helpful to consider the degree to which different causes of death contributed to the excess mortality observed. This approach reveals that $53 \%$ of the excess mortality was due to cancer, $4 \%$ to circulatory diseases, $7 \%$ to bronchitis, emphysema, and asthma, $10 \%$ to liver cirrhosis, $12 \%$ to other diseases, and $14 \%$ to external causes. These figures may reflect multiple effects of the exposures studied, or they may reflect a hypothetical opposite "healthy worker effect," as suggested by Wong, Bailey, \& Amsel.

However, an assessment of possible bias cannot be made by scrutinizing the study results per se. Instead, it is necessary to employ concrete knowledge about, for example, the health-based selection processes that have influenced the composition of the specific study population.

This basic principle can be illustrated by the actual case: Is it in any respect realistic to imagine that the job tasks typically conducted by mastic asphalt workers should preferentially attract subjects with health problems - or that the employers should seek out unhealthy subjects among the job applicants? Anyone who has attended the laborious jobs performed by a gang of mastic asphalt workers will find the aforementioned suggestions absurd. All of the job tasks involve a heavy physical work load, and, moreover, the persons recruited the most recently carry out the heaviest tasks. In addition, the heat irradiation and the fumes emitted by the hot asphalt would be intolerable to many people of poor health.

As regards the mastic asphalt workers, it is therefore probable that an effective selection for health, strength, and fitness has been at work. This assumption gains further credibility from a note made by the Danish asphalt industry that in 1978 the sick leave percent for hourly paid asphalt workers had been less than half the average for all laborers employed by members of the Danish Employers' Association (3). 


\section{Age pattern}

Wong, Bailey, \& Amsel argue "...that the overall mortality excess came primarily from the younger age groups." This is not a valid statement. The argument seems to be based on SMR (ie, standardized mortality ratio) comparisons - a method that is untenable for trend analyses. As a matter of fact, the age group $15-39$ years contributed $12 \%$ of the excess number of deaths (all causes combined), the age group 40-64 years contributed $70 \%$, and the age group $65-89$ years accounted for $18 \%$.

With regard to the high mortality seen among the young mastic asphalt workers (aged 15-39 years), 7 of the 11 deaths in this group were due to external causes. The striking observation of three deaths from circulatory diseases in this age group (expected 0.34) was conferred additional attention in the mortality paper (2). The types of diagnoses involved do not support the strange theory that young persons of poor health should have been preferentially selected for work as mastic asphalt workers.

\section{External causes of death}

The high mortality from external causes among the mastic asphalt workers deserves some attention, as it may indicate an above-average risk-taking behavior. Out of a total of 17 deaths due to external causes (expected 7.61), nine were due to suicides (expected 3.57) and two to occupational accidents. As regards the excess mortality from suicides, correction for regional differences (4) leads to an SMR equal to 135 [95\% confidence interval $(95 \% \mathrm{CI}) 62-256]$. No figures are available as regards the expected number of deaths from occupational accidents, but, no doubt, two deaths constitute an extreme excess in this small population.

\section{Liver cirrhosis}

The mortality from liver cirrhosis was significantly increased. Even after correction for regional differences (4), a doubling of the cirrhosis mortality remained (2) (SMR 197, 95\% CI 79-406).

Regrettably, no data on drinking habits are available. But if an excess number of alcoholics has been included in the study cohort, it would be expected to increase the mortality from liver cirrhosis and to influence the incidence of certain cancers. It is, however, unlikely that alcohol alone should create a doubling of the incidence of respiratory cancer. [The standardized morbidity ratio for respiratory cancer equaled 214 (95\% CI 145-304) after correction for smoking habits and regional differences (1)].

The possibility of hepatotoxic exposures in the workplace should not be neglected either. Cutback bitumen (ie, bitumen mixed with an organic solvent) presents an obvious guess. In addition, the possibility that the hot mastic asphalt emits hepatotoxic substances should be considered.

\section{Influence of smoking habit differences}

The adjustment for smoking habit differences adhered to strata defined by daily consumption measured in grams of tobacco. The adjustment relied on tobacco consumption data recorded in a population survey in 1982 (5) and a survey of active Copenhagen mastic asphalt workers in 1976 (6). [The list of workers included in the latter survey made up one of the sources (number 10) for the identification of persons eligible for inclusion in the follow-up study. The smoking data obtained from the 1976 survey probably overestimate the tobacco consumption in the older subgroups of the cohort of mastic asphalt workers. However, the 1976 survey provides the only historical data available on smoking habits among mastic asphalt workers.] The relative risk (RR) estimates for lung cancer for different tobacco consumption strata were derived from Doll \& Peto's follow-up study on male British doctors (7).

Whereas the population survey (5) employed a smoker stratification equal to that used by Doll \& Peto (7), the survey of mastic asphalt workers (6) employed different strata, namely (daily tobacco consumption) $0 \mathrm{~g}, 1-9 \mathrm{~g}, 10-14 \mathrm{~g}, 15-20 \mathrm{~g}$, and $\geq 21 \mathrm{~g}$. Unfortunately, the latter two strata are not comparable to any of the strata employed by Doll \& Peto (7).

However, if the extreme assumption is made tha: all of the mastic asphalt workers in the category $\geq 21 \mathrm{~g}$ have in fact been smoking $25 \mathrm{~g}$ or more, and, furthermore, if the relative risk estimate relating to persons smoking $15-24 \mathrm{~g}$ daily (7) is used for the mastic asphalt workers smoking $15-20 \mathrm{~g} \mathrm{(6)}$, smoking habit differences would "explain" no more than a $21 \% \mathrm{ex}$ cess of lung cancer.

On the contrary, if it is assumed that all of the mastic asphalt workers in the category $\geq 21 \mathrm{~g}$ have smoked less than $25 \mathrm{~g}$ a day, the smoking habit differences would "explain" a $1 \%$ excess of lung cancer among the mastic asphalt workers.

These maximum and minimum figures make it obvious that confounding by smoking habit differences is hardly of any major importance. For reasons of simplicity, I therefore merged the groups who smoked at least $15 \mathrm{~g}$ of tobacco a day into a single stratum (1-2). The relative risk estimate applied to this $\geq 15 \mathrm{~g}$ stratum was calculated as the mean of Doll \& Peto's relative risk estimates for the strata $15-24 \mathrm{~g}$ and $\geq 25 \mathrm{~g}$ (7).

Wong, Bailey, \& Amsel ask for a smoking correction specific for histological types of lung cancer. With regard to the lung cancer types recorded for the mastic asphalt workers, I think the most impressive observation was that of three nonsmokers with "smoker carcinomas" (two cases of anaplastic carcinoma and one squamous cell carcinoma) (1). In Denmark, smoking-related lung cancers constitute the overwhelming 
majority of primary lung cancer cases. Separate calculations of expected numbers for histological subgroups of lung cancer have not been made because histology-specific rates are not available. However, even if such calculations were made, smoking habit correction for histological subgroups of lung cancer would hardly alter the conclusion because of the minimal differences in smoking habit distribution between the groups compared and the high background frequency of tobacco smoking among Danish men.

\section{Influence of regional differences}

As mentioned in the original papers (1-2), adjustments for regional differences were based on data published by the Danish National Bureau of Statistics (4) and the Danish Cancer Registry (8). Wong, Bailey, \& Amsel express their surprise over the fact that the "urbanization" correction factor for cancer incidence differed from that for cancer mortality. This feature is not surprising. It reflects the significant differences between cancer registry data and death certificate data with regard to type and quality.

\section{Influence of social-class differences}

The issue of social class differences is not explicitly raised in the preceding letter. However, the concept of "confounding by social class" underlies much of the criticism presented by Wong, Bailey, \& Amsel. Fortunately, it is possible to add some data relating to this topic.

For the 10-year period 1970-1980 the Danish National Bureau of Statistics has published mortality data for all major occupational groups (9). The following SMR values relate to the group "unskilled concrete workers" (which includes mastic asphalt workers), "all occupationally active males" being the standard of comparison: overall SMR 98, cancer SMR 102, digestive cancer SMR 103, respiratory cancer SMR 97, circulatory diseases SMR 88 , bronchitis, emphysema, and asthma SMR 143, liver cirrhosis SMR 101, and external causes of death SMR 140 (9).

These figures indicate that the mastic asphalt workers' peer group does not break away from occupationally active males in general with regard to overall mortality, respiratory cancer, digestive cancer, or liver cirrhosis.

\section{Analyses}

Failing to give any substantial argument, Wong, Bailey, \& Amsel question the truth of my explanation for not analyzing site-specific cancer mortality (2). If they find their question important, they can check the information given by me by communicating with the appropriate Danish authorities.

With regard to the age (and period) standardization, it was based on 5-year groups.
The lung cancer incidence data were analyzed by year-of-birth subcohorts also. This procedure was carried out to throw light on the consequences of exposure during World War II, a period during which coal-tar pitch was used. Wong, Bailey, \& Amsel pay particular attention to the two men with lung cancer who were born in 1930 and 1931, and they argue that these two persons could have been exposed during World War II and therefore could have been exposed to coal-tar pitch. World War II ended in 1945, at which time persons born in 1930 were $14-15$ years of age. It is pure speculation to allege that persons born in 1930 or later have been mastic asphalt workers during World War II.

Still referring to the subcohort analyses of lung cancer incidence, Wong, Bailey, \& Amsel further claim that "A misclassification of even one case would have changed the result." This statement is not valid. The only type of misclassification that may be of relevance in the actual context is diagnostic underascertainment. If one wants to blame misclassification for the subcohort pattern observed, one has to assume the occurrence of at least 40 undiagnosed lung cancer cases in the two oldest subcohorts (subcohorts I and II). This is hardly a realistic assumption.

Wong, Bailey, \& Amsel also mention the fact that the three lung cancer cases in the youngest subcohort (subcohort III) occurred in smokers. This is not a surprising finding. I think that most oncologists would be extremely surprised to find a primary lung cancer in a nonsmoking person at age 50 years or younger. However, it is well recognized that contributory causes of cancer (eg, occupational factors) manifest themselves by accelerating the occurrence of malignant disease.

Moreover, Wong, Bailey, \& Amsel provide the reader with a calculation, the origin of which is obscure. They claim that "On the basis of the numbers reported, the lung cancer SMR for those aged less than 40 years. . . was calculated to be 370 ( 4 observed versus 1.08 expected).' However, no case of lung cancer was observed in persons younger than 44 years (1). The calculation and the matching conclusion presented by Wong, Bailey, \& Amsel lacks any correspondence with reality.

\section{Co-exposure to coal tar?}

In their letter, Wong, Bailey, \& Amsel indicate "sources in the Danish asphalt industry" for the statement that " . . both tar oil and tar pitch were used in the asphalt industry in Denmark up to as recently as $1975 . .$. " This statement agrees with current knowledge about the use of coal tar as an adhesion-promoting agent in the production of so-called powder asphalts for carpet paving.

However, what matters in the actual context is the question of whether coal tar has been used in the mastic 
asphalt industry. Wong, Bailey, \& Amsel make a statement that is of relevance in this context, namely, that "... coal tar was used in leveling the 'base' asphalt layer (so-called 'pulver' asphalt) until the earlier 1970s."

Here, the industry representatives make an important statement. If the mastic asphalt workers were exposed to significant amounts of coal-tar fumes, it is necessary to reassess the implications of the increased cancer risk observed.

However, it should be noted that until the appearance of the first report which indicated an increased cancer risk among Danish mastic asphalt workers (10), the representatives of the Danish mastic asphalt industry denied that their products contained coal tar. In particular, the recent statement about coal-tar use is in conflict with the information given to the mastic asphalt workers throughout the whole postwar period.

Wong, Bailey, \& Amsel support their statement about coal-tar use by referring to the Occupational Health Center of the Danish Asphalt Industry. Recently, I met with representatives of this organization to learn more about the possible coal-tar exposure in the mastic asphalt industry. At that instance, I saw a report prepared by the Center on the substances used in the mastic asphalt industry in the past. I was allowed to look through this report but I was not allowed to obtain a copy. At first glance, I was impressed by the many instances in which the report mentioned the use of significant amounts of coal tar. I was disappointed, however, by the lack of references or other types of documentation given in the report.

In April 1991 the US Asphalt Institute performed a study on core samples from Copenhagen streets. According to the investigators, the analyses demonstrate the presence of coal tar in the layer of ventilation asphalt placed underneath the mastic asphalt (personal communication, $\mathrm{Mr}$ AJ Kriech). Despite limitations in the documentation given, these results seem to warrant attention. It would be interesting if the results reported by the US Asphalt Institute could be replicated in a controlled study with blinded analyses and readings.

\section{Closing remarks}

The most serious methodological question raised in the preceding letter concerns selection bias. Scrutiny of the possible sources of such bias has revealed minor imperfections which all imply underestimation of the relative morbidity or mortality of the mastic asphalt workers studied. As regards the increased overall mortality observed among the mastic asphalt workers, common sense rules out the theory put forward by Wong, Bailey, \& Amsel that individuals with health problems should have been overrepresented among the persons hired into the mastic asphalt industry. As regards the confounding control performed (1-2), much of the criticism raised by Wong, Bailey, \& Amsel proved to be based on misunderstandings. In conclusion, it seems unlikely that the high risks observed for respiratory and digestive cancer have been due to confounding or other types of bias.

Wong, Bailey, \& Amsel allege that exposure to coal tar has been important. However, appropriate documentation for this assertion seems to be lacking. If exposure to coal-tar fumes should "explain" the lung cancer risk observed, it is necessary to assume that the mastic asphalt workers have been exposed at levels comparable with those of the most heavily exposed gas workers employed at British gas boards within the first half of this century (11). This seems to be an unrealistic assumption. Yet another aspect of relevance for the exposure discussion is that exposure to coal tar usually causes a marked increase in the risk of skin cancer (11). No excess risk of skin cancer was observed among the mastic asphalt workers (SMR 78, 95\% CI 21-199) (1) in spite of the fact that they have primarily been working outdoors. The low incidence of skin cancer seen among the mastic asphalt workers speaks against the theory that these workers should have been exposed to significant amounts of coal tar.

As regards the biological activity of bitumen fumes, the National Institute for Occupational Safety and Health (NIOSH) has recently provided experimental data indicating that these fumes contain potent carcinogens which are not polycyclic aromatic hydrocarbons. Almost all of the biological activity found in the fume condensate was found in two chemical fractions, namely, one containing alkylated phenylethanones and alkylated dihydrofuranones (tumors in $100 \%$ of the animals) and another containing olefins, alkylated aryl thiophenes, and alkylated phenanthrenes (tumors in $60 \%$ of the animals) (12).

All over the world, huge numbers of workers are exposed to bitumen fumes during asphalt production, road building, waterproofing, roofing, flooring, and the like. It is therefore important to reach a sound and well-founded judgement as regards the health effects of bitumen fumes.

\section{References}

1. Hansen ES. Cancer incidence in an occupational cohort exposed to bitumen fumes. Scand J Work Environ Health $1989 ; 15: 101-5$.

2. Hansen ES. Mortality of mastic asphalt workers. Scand J Work Environ Health 1991;17:20-4.

3. Asfaltindustriens Oplysningskontor for Vejbygning. Målinger og undersøgelser af asfaltrøg [Measurements and analyses of asphalt fumes]. Asfalt 1980;69:7.

4. Danmarks Statistik. Regionale dødelighedsforskelle i Danmark 1971 - 79 [Regional variation in mortality in Denmark 1971-1979]. Copenhagen: Danmarks Statistik, 1985. (Statistiske undersøgelser $\mathrm{nr} 39$ ).

5. Madsen F, Hedegaard L, Sjøl A. Lungesymptomer og lungefunktioner [Respiratory symptoms and lung functions]. In: Hagerup L, ed. Sygdom og sundhed - befolkningsundersøgelserne i Glostrup [Illness and health - the population surveys in Glostrup]. Glostrup: Glostrupgruppen, 1987:57-75.

6. Hasle P, Hegelund G, Høgh K, Jensen C, Jensen E, Jen- 
sen TF, et al. Asfaltarbejde - en arbejdsmiljøundersøgelse [Handling of asphalt - a study on working environment]. Roskilde: Roskilde Universitetsforlag, 1977.

7. Doll $\mathbf{R}$, Peto $\mathbf{R}$. Mortality in relation to smoking: 20 years' observations on male British doctors. Br Med J 1976;2:1525-36.

8. Danish Cancer Registry. Incidence of cancer in Denmark 1973-1977. Copenhagen: Danish Cancer Registry, 1982.

9. Danmarks Statistik. Dødelighed og erhverv 1970-1980 [Mortality by occupation 1970-1980]. Copenhagen: Danmarks Statistik, 1985. (Statistiske undersøgelser nr 41).

10. Hansen ES, Berendt FB. Dødelighed og kræftforekomst blandt danske støbeasfaltarbejdere 1959-1986 [Mortality and cancer incidence among Danish mastic asphalt workers 1959-1986]. Odense: Odense Universitetsforlag, 1988.

11. Doll R, Vessey MP, Beasley RWR, Bückley AR, Fear EC, Fisher REW, et al. Mortality of gasworkers - final report of a prospective study. Br J Ind Med 1972;29: 394-406.

12. Sivak A, Menzies K, Beltis K, Worthington J, Ross A, Latta R. Assessment of the cocarcinogenic/promoting activity of asphalt fumes. Cincinnati, $\mathrm{OH}$ : US Department of Health and Human Services, 1989.

\section{Appendix}

The historical sources from which the mastic asphalt workers were enrolled

Source 1: Employment list from the Copenhagen Asphalt Company. The list contains identification data on laborers employed within the period 1920-1974. It was handed over by the plant management to Dr O Horwitz and Dr F Behrendt before 1 January 1978. Date of entry into the study: 1 January 1978. A total of 10 workers ( 35 records in the raw data) was enrolled from this source.

Source 2: Extract of an employment list covering the period 1936-1973 from the Danish Asphalt Plant, Copenhagen division. The extract contains only those laborers on the employment list who had been employed continuously for at least six months. The extract was performed by $\mathrm{Dr} \mathrm{O}$ Horwitz. It has not been possible to trace the original employment list, which was handed over by the plant management to $\mathrm{Dr} O$ Horwitz and Dr F Behrendt before 1 January 1978. Date of entry into the study: 1 January 1978 . A total of 223 workers ( 305 records in the raw data) was enrolled from this source.

Source 3: Employment file (cards) from the Danish Asphalt Plant, Nysted division. The file contains identification data on laborers employed within the period 1955-1963. It was handed over by the plant management to Dr O Horwitz and Dr F Behrendt before 1 January 1978. Date of entry into the study: 1 January
1978. A total of 40 workers ( 60 records in the raw data) was enrolled from this source. (NOTE: Nysted is a village located in the Lolland-Falster region, far from Copenhagen or other city areas. The location of a mastic asphalt plant at this place has primarily been due to the local occurrence of a special type of limestone. The limestone quarry in Nysted was owned by the mastic asphalt plant. About one-third of the persons in source 3 may not have been mastic asphalt workers; instead they could have been limestone quarry workers.)

Source 4: Undated employment list from the Copenhagen Asphalt Company. The list contains identification data on laborers employed on the date of compilation. The list was compiled by the plant management before 1 January 1961. Date of entry into the study: 1 January 1961. A total of 41 workers (57 records in the raw data) was enrolled from this source.

Source 5: Employment list, dated 7 July 1960, from the Thorning Christensen Plant. The list contains identification data on laborers employed on the date of compilation. The list was compiled by the plant management. Date of entry into the study: 7 July 1960 . A total of 15 workers ( 18 records in the raw data) was enrolled from this source.

Source 6: Undated employment list from the Hans Guldmann Company A/S. The list contains identification data on laborers employed on the date of compilation. The list was compiled by the plant management before 1 January 1961. Date of entry into the study: 1 January 1961. A total of 42 workers (53 records in the raw data) was enrolled from this source.

Source 7: Employment list, dated 5 October 1972 from the Hans Guldmann Plant A/S. The list contains identification data on laborers employed on the date of compilation. The list was compiled on request of the union of mastic asphalt workers on occasion of a quarrel about a case of a person being fired. Date of entry into the study: 5 October 1972. A total of 29 workers ( 32 records in the raw data) was enrolled from this source.

Source 8: List, dated 26 November 1980 , compiled by the Copenhagen union of mastic asphalt workers. The list contains identification data on laborers known to be or to have been handling cork asphalt at the Danish Asphalt Plant, Copenhagen division. The list was compiled in order to give information to the local occupational safety and health administration in the region 
in question. Date of entry into the study: 26 November 1980. A total of seven workers (11 records in the raw data) was enrolled from this source.

Source 9: Entry forms (cards) of the Copenhagen union of mastic asphalt workers. The file contains identification data on persons who entered the union within the period 1 January 1974 through 31 December 1979. Date of entry into the study: individual date of entry into the union as recorded on the entry form. A total of 67 workers ( 75 records in the raw data) was enrolled from this source.

Source 10: Mailing list used for a questionnaire-based survey concerning health, work environment, and personal habits. The survey, which was conducted in October 1976, comprised all active workers organized in the Copenhagen union of mastic asphalt workers. The list was compiled by the union in September 1976. Date of entry into the study: 1 October 1976. A total of 112 workers (129 records in the raw data) was enrolled from this source.

Source 11: Membership file (cards) of the benefit society organized by the workers at the Danish Asphalt
Plant, Copenhagen division. The file contains identification data on persons who had been members of the society during any time within the period 1 January 1959 through 31 January 1979. Date of entry into the study: Individual date of entry into the benefit society as recorded on the membership card. A total of 38 workers (94 records in the raw data) was enrolled from this source.

Source 12: List from the aforementioned benefit society. (See source 11.) The list contains identification data on recipients of compensation (from the benefit society) for lost wages. It covers the period 1960 through 1966. Date of entry into the study: 1 July in the year in which the person was noted for the first time on the list of payment recipients. A total of 55 workers (116 records in the raw data) was enrolled from this source.

\section{Eva Støttrup Hansen, MD}

Institute of Social Medicine

University of Copenhagen

Panum Institute

Blegdamsvej 3

DK-2200 Copenhagen N, Denmark 